\title{
New fungus-feeding thrips (Thysanoptera-Phlaeothripinae) from tropical Australia
}

\author{
LAURENCE A. MOUND ${ }^{1} \&$ KAMBIZ MINAEI ${ }^{2}$ \\ ${ }^{1}$ CSIRO Entomology, GPO Box 1700, Canberra ACT, Australia 2601.E-mail: Laurence.Mound@ csiro.au \\ 2 Plant Protection Department, College of Agriculture, Tehran University, Iran
}

\begin{abstract}
Three new genera and seven new species of fungal-feeding thrips are described from the northern, tropical zone of Australia. Majerthrips barrowi gen. et sp. n. is a large species exhibiting polymorphism associated with wing development and sex, whereas Senithrips psomus gen. et sp. n. is a minute monomorphic species with little sexual dimorphism. Also monomorphic is Jacotia rhodorcha sp.n., the fourth species described in this genus from Australia. These three were all taken during a biodiversity survey of Barrow Island, Western Australia. Structural variation in Streptothrips tribulatius sp. n. from Cape Tribulation, Queensland, confirms the existence of dimorphism in this genus between winged and wingless individuals. Stomothrips mouldeni differs from the single described species in this genus in having the mouth cone directed ventrally not posteriorly; it was collected from Cycas pruinosa in the north of Western Australia. Also in this area but living at the base of Triodia grasses, Apostlethrips apostus and A. pygus gen. et spp. n. are remarkable amongst the Eurythrips group of leaf-litter phlaeothripines in lacking sense cones on antennal segment III, and lacking tergal wing retaining setae in macropterae, also in the setose abdominal apex.
\end{abstract}

Key words: Thysanoptera, Phlaeothripidae, Australia, new genus, new species, fungus feeding, polymorphism

\section{Introduction}

The number of described Thysanoptera species recorded from Australia has risen sharply in recent years, from 287 in 1970 (CSIRO Textbook) to 685 in 2005 (see checklist published by the Australian Biological Resources Study http://www.deh.gov.au/ biodiversity/abrs/online-resources/fauna/afd/group.html). Much of this descriptive effort has been, and continues to be, targeted at particular genera or at groups of species associated with particular host plants, because such approaches lead to a better 
understanding of the biology and radiation of Thysanoptera. However, in the Australian

National Insect Collection, Canberra, there are many undescribed thrips taxa that fall outside major genera, as well as many that are known only from single samples or even single individuals. Published information thus involves an underestimate of the structural and biological diversity among the Australian members of this order of insects, and the limited objectives of this paper are to publish formal descriptions of some taxa that are represented by good material.

Three new genera are described here, two with one new species and one with two, also one new species is described in a genus not previously recorded from Australia, as well as one new species in each of two genera that were previously recorded in Australia from only one or a few species. All of these taxa are members of the subfamily Phlaeothripinae, and they probably all feed on fungi. Six of the species live at ground level, in grass tussocks or on dead leaves and twigs, but the seventh lives on the leaves of Cycas pruinosa, apparently feeding on fungal conidia. Each of these species has been taken in northern Australia; three from Barrow Island near Karratha in the north-west of Western Australia, three from between Broome and Kununurra in the north-west, and one from Cape Tribulation on the north-east coast.

\section{Acknowledgements}

The material discussed below from Barrow Island was derived from a terrestrial invertebrate biodiversity survey organised by Prof. Jonathan Majer of Curtin University. The material from near Broome and Kununurra was collected as part of a thrips survey organised by Tony Postle of the Northern Australia Quarantine Service. Holotypes are deposited in the Australian National Insect Collection, Canberra. The authors are grateful for the opportunity to study this material, also for research facilities provided by CSIRO Entomology, Canberra. The Ministry of Science, Research and Technology, Iran, also Tehran University, provided funding for a study visit to Canberra by Kambiz Minaei.

\section{Apostlethrips gen.n.}

Medium sized, winged or apterous Phlaeothripinae. Antennae 8-segmented, VI-VIII distinct but broadly connected (Figs 3, 4); III with no major sense cones, IV with 2 sense cones. Head longer than wide, prolonged in front of eyes, cheeks constricted behind eyes, with almost no sculpture; ocellar and postocular setae stout and weakly capitate (Figs 1, 2); maxillary stylets wide apart, low in head. Pronotum transverse, without sculpture; notopleural sutures incomplete; anteromarginal, anteroangular and midlateral setae no larger than discal setae, notopleural setae stout and weakly capitate. Mesonotal lateral setae small, spiracles large with complex internal sculpture. Metanotum without sculpture 
medially. Prosternal basantra large with transverse posterior margins, ferna pointed medially, spinasternum with 2 setae, mesopraesternum slender and transverse; metathoracic sternopleural sutures not developed. Forewing without duplicated cilia, three sub-basal setae capitate. Fore tarsus with or without small, slender, curved tooth in both sexes. Pelta without sculpture; spiracles on segment I large but spiracles not developed on VIII; tergites II-VII with one or two pairs of stout weakly capitate marginal setae but no wing retaining setae; tergite IX setae capitate; tube tapering, anal setae shorter than width of tube apex (Figs 5,6). Sternites with prominent marginal setae; no glandular areas in either sex.

Type species Apostlethrips apostus sp.n.

\section{Comments}

This new genus is similar in general appearance to many of the species of Eurythrips Hinds that are so common in leaf litter in eastern North America (Mound, 1976, 1977). In common with the members of that genus the prosternal basantra are well-developed, and the pronotal anteromarginal and anteroangular pairs of setae are not elongate. Both species described here differ from all Eurythrips (and also most Phlaeothripidae worldwide) in having no major sense cones on the third antennal segment (a minute sense cone is present on the external apical margin in a few individuals). Moreover, there appear to be no spiracles on abdominal segment VIII, whereas the mesothoracic spiracles are greatly enlarged with complex internal structure. Also unusual are the following character states: wing retaining setae absent even in macropterae; major setae stout and capitate; tube slender but with anal setae short. These two species were both found at ground level amongst the tussocks of spinifex grasses in the north of Western Australia, where they probably feed on fungal hyphae. The most common fungus feeding Phlaeothripinae living at ground level in Australia, usually in leaf litter, are members of the genera Psalidothrips Priesner (Mound 1996) and Zemiathrips Mound (2002). In both of these, the species have the terminal antennal segments clearly distinct from each other rather than broadly joined. Moreover, Psalidothrips species differ in lacking prosternal basantra, and Zemiathrips species have unusually long body setae. This genus is named in recognition of the efforts of Tony Postle of the Northern Australia Quarantine Service in surveying the insect fauna of the North West.

Key to species

1. Antennal segment III about 1.5 times as long as wide (Fig. 3); head with one pair of stout ocellar setae (Fig. 1); fore tarsus with minute curved tooth in both sexes; notopleural sutures almost complete, posteroangular and notopleural setae equal in size; tergites II-VII with one pair of stout marginal setae; tergite IX with 3 pairs of stout setae (Fig. 5) apostus 
-. Antennal segment III more than 2.0 times as long as wide (Fig. 4); head with three pairs of stout ocellar setae (Fig. 2); fore tarsus without a tooth in either sex; notopleural sutures very short, notopleural setae arising from tubercle, posteroangular setae minute; tergites II-VII with two pairs of stout marginal setae; tergite IX with at least 6 pairs of stout setae (Fig. 6) pygus

Apostlethrips apostus sp.n.

(Figs 1, 3, 5, 7)

Female macroptera. Body and legs largely yellow, light brown shadings present on external margin of legs, anterior margin of head and apex of tube; antennal segments VI VIII light brown, IV-V brownish yellow; wings and major setae pale. Head with eyes slightly bulging, one pair of stout setae on anterior margins of ocellar triangle; postocular setae short (Fig. 1). Pronotum smooth with notopleural setae almost complete, posteroangular setae as long as notopleural setae. Mesonotum with some sculpture. Metanotum smooth medially with one pair of small stout setae; pelta small, occupying about half the width of tergite II; tergites II-VII with median setae small, posterior margins with one pair of stout setae and one pair of small setae, posteroangular setae straight (Fig. 7); tergite IX truncate with 3 pairs of stout setae; tube slender, dorsal pair of anal setae slightly capitate (Fig. 5).

Measurements. Holotype female in microns. Body length 1450. Head, length 175; maximum width 170; postocular setae 20; ocellar setae 20. Pronotum, length 125; median width 220; major setae am 10, aa 8, ml 8, epim 50, pa 40. Forewing length 660; basal setae 18, 33, 35. Tergite III, median discal setae 10; major marginal setae 25; posteroangular setae 20. Tergite IX setae S1 40; S2 65; S3 40. Tube length 150; dorsal anal setae 25. Antennal segments III-VIII length 37, 45, 45, 42, 35, 30.

Female aptera. Similar to macroptera but ocelli absent, meso and metanota with additional pairs of small setae.

Male aptera. Similar to female but smaller, body length 1270 .

\section{Material studied}

Holotype female macroptera. Western Australia, Fitzroy Crossing, Geike Gorge, from soft Triodia sp., 27.ii.2005 (LAM 4625).

Paratypes: 35 females 2 males taken with holotype.

Non-paratypic specimens: 1 female aptera, 1 female macroptera, from sticky Triodia sp., Kununurra Gorge, 23.ii.2005 (LAM 4577); 2 female apterae, 4 male apterae, 30km south of Wyndham, 26.ii.2005 (LAM 4619); 1 female aptera, Broome, coastal sand dunes, from base of Triodia sp., 28.ii.2005 (LAM 4640). 

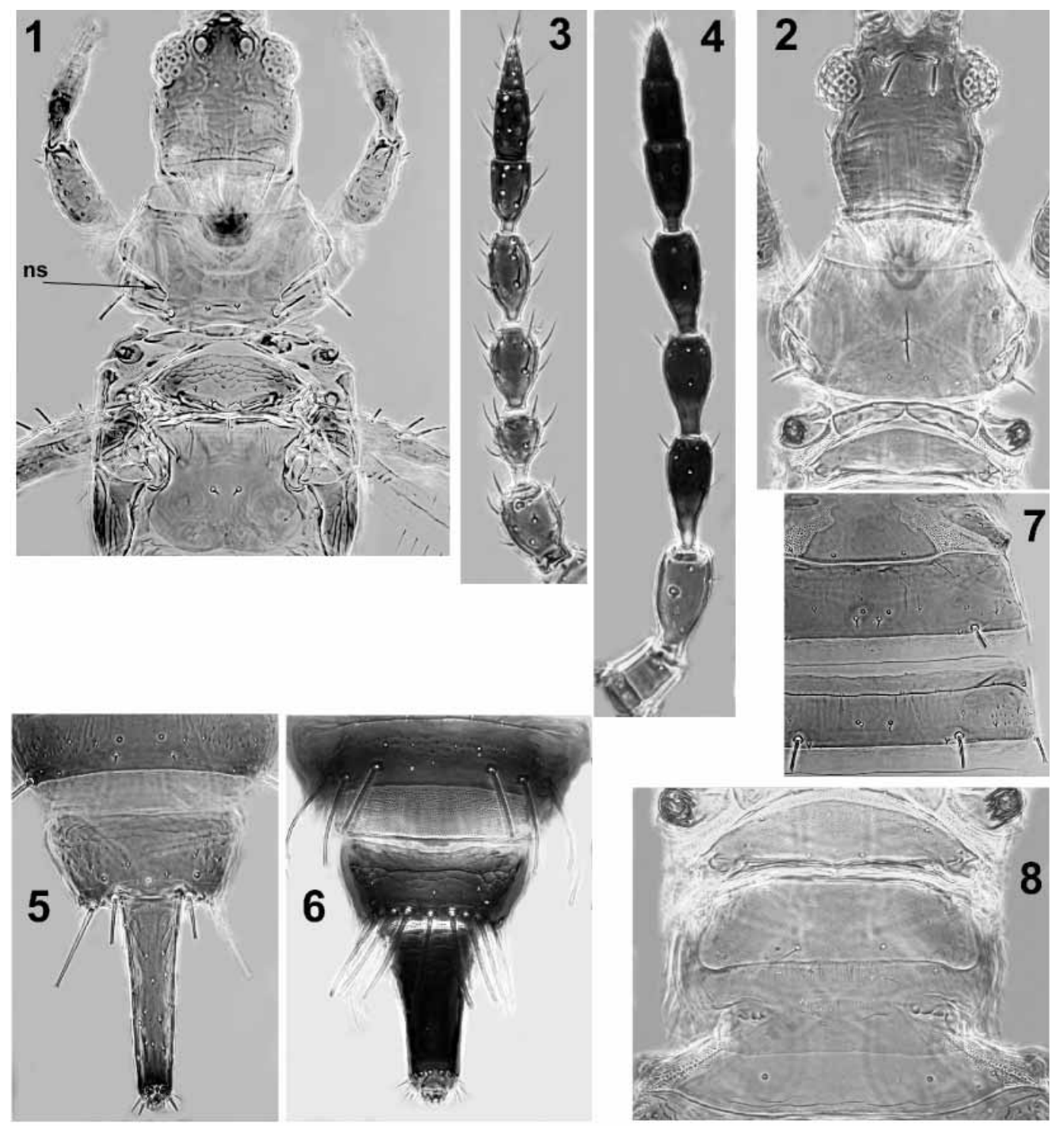

FIGURES 1-8. Apostlethrips species. 1, 3, 5, 7, A. apostus. 2, 4, 6, 8, A. pygus. (1, 2) Head and pronotum; (3, 4) Antenna; $(\mathbf{5 , 6})$ Tergites VIII-X; (7) Tergites I-III; (8) Pterothorax and pelta. [ns = prothoracic notopleural suture]

\section{Comments}

Of the available females, three are apterae, one (the holotype) is fully winged, but all the rest are de-alate with the distal half of the wings broken away. When alive, this species was noted to carry around on the apex of the abdomen a large plug of black material, although this was washed away in the collecting fluid. The two specimens (LAM 4577) excluded from the type series have abdominal tergites eight and nine more extensively dark brown, also the apex of the tube, and the macroptera has the lateral margins of the 
pterothorax brown. The remaining seven specimens (LAM 4619, 4640) have the tube uniformly dark brown with tergite IX also dark, and apparently lack a fore tarsal tooth.

\section{Apostlethrips pygus sp.n.}

(Figs 2, 4, 6, 8)

Female aptera. Body and legs mainly yellow; mesothoracic spiracle brown; abdominal segments VIII-X dark brown; antennal segments I-II yellow, III-VIII brown. Head with eyes bulging, cheeks sharply constricted behind eyes (Fig. 2); vertex projecting in front of eyes as two tubercles bearing antennae, with 3 pairs of stout setae and 3 pairs of minute setae between eyes; postocular setae short and stout, cheeks with one small stout seta. Antennae slender, segment II unusually elongate (Fig. 4). Fore tarsus with no tooth on inner margin. Pronotum with notopleural sutures almost fused, notopleural setae arise on distinct tubercles. Mesonotum transverse, spiracles exceptionally large (Fig. 8). Metanotum transverse with one pair of slender setae medially. Pterothoracic furcae stout, extending to coxal cavities. Pelta broad (Fig. 8), tergites II-VII with median setae small, two pairs of posteromarginal setae capitate; tergite IX tapering, with 8 pairs of stout setae (Fig. 6); tube tapering to apex from rugose base. Sternites with 7 pairs of marginal setae, these very stout on VI-VIII.

Measurements. Holotype female in microns. Body length 1550. Head, length 190; width across eyes 190; postocular setae 35; ocellar setae 35, 20, 15. Pronotum, length 125 ; median width 250 ; major setae am 10 , aa $10, \mathrm{ml} 10$, epim 40 , pa 15 . Tergite III, median discal setae 20; major marginal setae 50, 75; posteroangular setae 50. Tergite IX setae 75. Tube length 120. Antennal segments I-VIII length 40, 65, 60, 52, 55, 45, 35, 30.

Male aptera. Similar to female but smaller, body length 1400 .

\section{Material studied}

Holotype female aptera. Western Australia, Broome, coastal sand dunes, from base of Triodia sp., 28.ii.2005 (LAM 4640).

Paratypes: 5 females 6 males taken with holotype.

\section{Comments}

All of the available specimens are apterous, and the exceptionally strong development of the pterothoracic furcae suggests that winged forms are not likely to occur in this species. It is clearly closely related to A. apostus described above, but the array of stout setae on the ninth abdominal segment, and the curious shape of the eyes, are unique character states amongst members of this family. As with A. apostus, adults were observed to carry a plug of dark material on the abdominal apex with this curled over the body. 
Large polymorphic Phlaeothripinae-Docessissophothripini. Antennae 8-segmented, III with 1 sense cone, IV with 3 sense cones, VII and VIII broadly joined by oblique suture. Head about twice as long as wide, elevated in midline, narrowest just behind compound eyes (Fig. 10); postocular setae capitate; postocellar setae acute in microptera, capitate in aptera; maxillary stylets retracted to compound eyes, close together in midline, maxillary guides stout; mouth cone pointed. Pronotum transverse, four pairs of capitate major setae present, anteromarginals absent (present in aptera); notopleural sutures complete. Mesonotal lateral setae capitate; metanotum reticulate, transverse in aptera; metanotal median setae acute (capitate in aptera). Prosternal basantra absent, ferna varying from pointed to rounded medially (Fig. 9); mesopraesternum complete but eroded, particularly in aptera. Metathoracic sternopleural sutures long and curved (Fig. 9), sometimes reaching almost hind coxal cavity. Both sexes with large fore femora and fore tarsal tooth. Forewings variable in length, also form of sub-basal setae, reaching thoracic hind margin in microptera, reaching tergite II hind margin in hemimacroptera. Pelta variable, quadrate to D-shaped (Fig. 10), but narrowly bell-shaped in aptera (Fig. 11); tergites II-VI each with 2 pairs of sigmoid wing-retaining setae, in microptera these are strongly developed only on III and IV, on VII they are short and straight as on all tergites of aptera; tergites with one pair of capitate posteromarginal setae, aptera with one pair of capitate setae medially (Fig. 11); tergite IX setae S1, S2 and S3 capitate in both sexes. Sternites III-VI of both sexes anterolaterally with areas of specialised reticulation; sternal discal setae small in single transverse row.

Type species Majerthrips barrowi sp.n.

\section{Comments}

The type species of this new genus has long maxillary stylets that are about 5microns in width, more slender than those of Idolothripinae species but broader than those of typical Phlaeothripinae. These stylets are very similar in their width, and in their length and position medially within the head, to those found in species of the phlaeothripine tribe Docessissophothripini (Mound \& Palmer, 1983). Moreover, as in most members of that tribe, the pelta is not broad, particularly in apterae, and the males have distinctive iridescent reticulate sculptured areas on sternites III to VII of the abdomen. Two genera of this tribe are known from Australia. Holothrips Karny includes species from around the world, and these have antennal segments VII and VIII more or less fused, and segments III and IV have three and four sense cones respectively. Asemothrips Hood is used for a group of small species, five Australian and one Indonesian, but these have antennal segments III and IV with two and four sense cones respectively. In contrast, the new species described below has segments III and IV with one and three sense cones respectively. All of the species in the Docessissophothripini appear to be fungus feeders on dead plant tissues. This new species is unusual amongst the members of this tribe in exhibiting polymorphism 
related to wing development as well as sex. The genus is named in recognition of the many contributions of Jonathan Majer to the studies of Australia's biodiversity.

\section{Majerthrips barrowi sp.n.}

(Figs 9-11)

Male microptera. Body bicoloured, head, thorax and pelta brownish yellow, abdomen brown; legs and antennae yellowish washed with light brown, antennal segments VI-VIII light brown; forewing remnant, and all major setae, pale. Head with reticulate sculpture, particularly posterolaterally; ocelli slightly reduced. Antennal segments V and VI with apices asymmetric. Pronotum with strong median apodeme. Tergites II-VII medially with conspicuous pair of campaniform sensilla and about 6 small setae; tergite IX setae S2 slightly shorter than S1 and S3 but equally capitate.

Measurements. Holotype male in microns. Body length 2600. Head, length 350; median width 200; postocular setae 50. Pronotum, length 200; median width 370; major setae am 10, aa 30, ml 40, epim 50, pa 40. Mesonotum lateral setae 20. Forewing length 150; basal setae 30 . Tergite III median discal setae 20; major marginal setae 50; posteroangular setae 30. Tergite IX setae S1 80; S2 40, S3 80. Tube length 180; basal width 100; distal width 50. Antennal segments III - VIII length 100, 80, 75, 70, 50, 25.

Female microptera. Slightly larger than male but very similar in structure, except fore tarsal tooth a little smaller. Body length 2950.

Female hemimacroptera. Similar to microptera but with ocelli fully developed.

Female aptera. Larger than but generally similar to microptera, except as follows. Body and legs brownish yellow, tube dark brown. Head with ocelli small, postocellar setae short and capitate. Pronotal anteromarginal setae short and capitate. Metanotum transverse, median setae capitate; wing remnant and axillary sclerites not developed. Pelta small and bell-shaped; tergites II-VII with one pair of median setae capitate.

Measurements of female aptera in microns. Body length 3400. Head, length 430; median width 240; postocular setae 50; postocellar setae 25. Pronotum, length 300; median width 450; major setae am 15 , aa $30, \mathrm{ml} 30$, epim 55, pa 30 . Tergite III median discal setae 35; major marginal setae 50; posteroangular setae 30 .

Male aptera. Similar to female; tergite IX S2 apparently absent; sternites with iridescent reticulation laterally well-developed.

\section{Material studied}

Holotype micropterous male, Western Australia, Barrow Island, beating vegetation at head height in gulley, April/May, 2005, Jonathan Majer.

Paratypes: $30^{x} 6$ 우 micropterae 2 우 $10^{x}$ aptera, collected with holotype. 

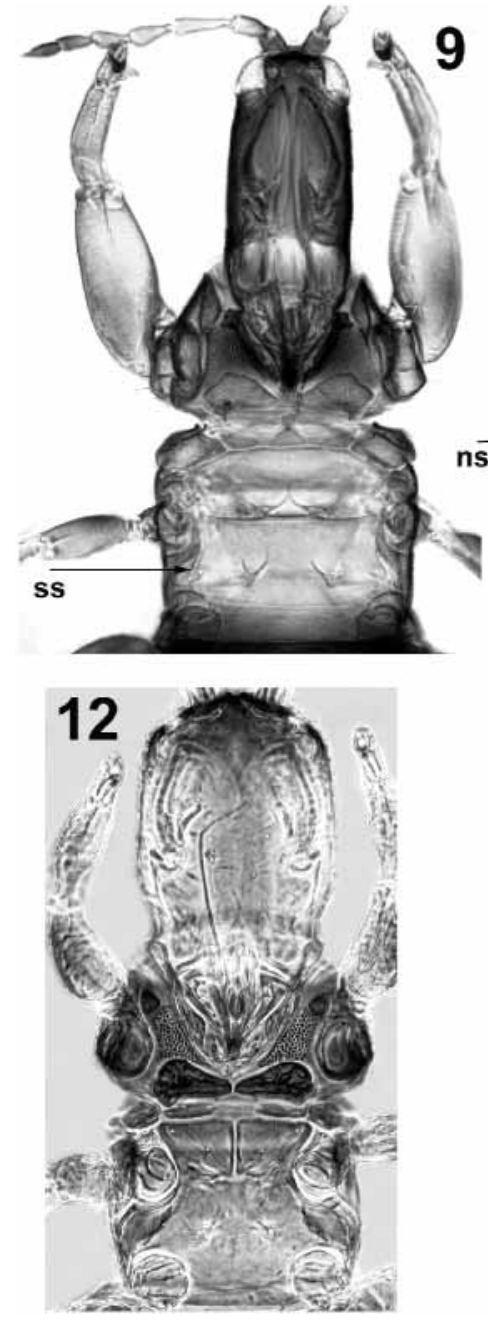
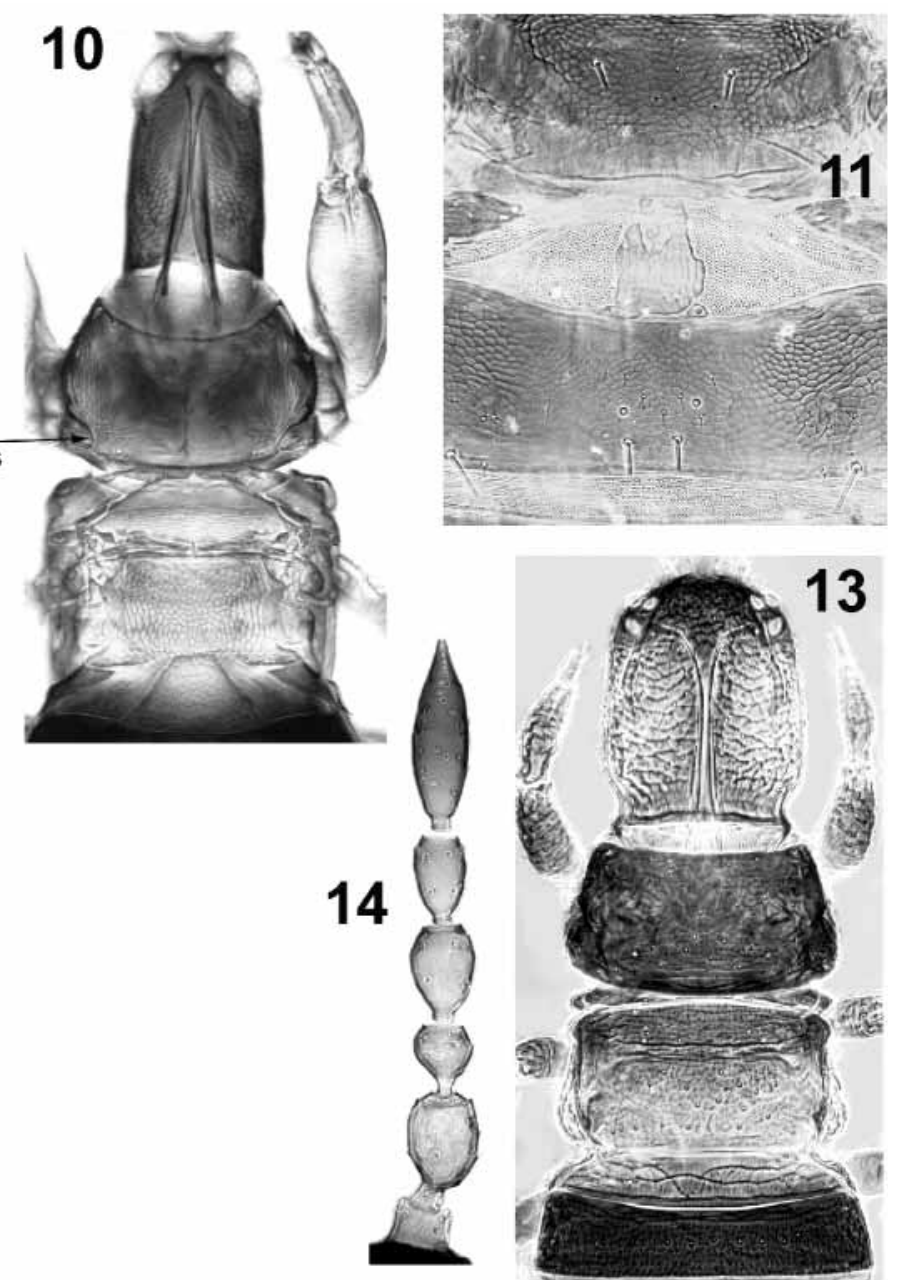

FIGURES 9-14. Majerthrips and Sennithrips species. (9) M. barrowi micropterous female, ventral; (10) $M$. barrowi micropterous female, dorsal; (11) M. barrowi apterous female, metanotum and tergites I-II; (12) S. psomus, ventral; (13) S. psomus, dorsal; (14) S. psomus antenna. [ns = prothoracic notopleural suture; ss = metathoracic sternopleural suture]

\section{Senithrips gen. $\mathbf{n}$.}

Minute apterous Phlaeothripinae, lacking ocelli and wing sclerites. Head longer than wide, cheeks convex but constricted at basal neck (Fig. 13), vertex rounded and slightly overhanging antennal bases, dorsal surface reticulate with three rows of small setae; compound eyes each reduced to 6 facets; maxillary stylets retracted to eyes and closely parallel medially, mouthcone short and rounded. Antennae 6-segmented (Fig. 14), III small without sense cones, IV with 2 sense cones, VI-VIII fused with no trace of sutures. Pronotum transverse, all setae minute, notopleural sutures apparently fused. Meso- 
metanotal suture apparently fused, metanotum broader at posterior, all setae small.

Prosternal basantra absent, ferna transversely oval, mesopraesternum eroded medially but forming two transverse sclerites (Fig. 12), mesoeusternum with median longitudinal division; meso-metathoracic sternopleural sutures not developed. Pelta broad but slender, reticulate with submarginal line (Fig. 13); tergites II-VII finely sculptured, with transverse row of more than 12 small setae, posterior margin with one pair of small curved setae laterally, and one pair of curved posteroangular setae; tergite IX setae S1 capitate, S2 blunt, S3 acute; tube short with short terminal setae. Male similar to female; no sternal glandular areas; tergite IX setae S2 stout.

Type species Senithrips psomus sp.n.

\section{Comments}

The antennae of the type species of this new genus, with segments VI-VIII fused into a single unit, are similar in structure to the antennae of Hexadikothrips dalbyi Crespi, Morris \& Mound (2004). However, the male of $H$. dalbyi has a well developed fore tarsal tooth as well as a small glandular area on the eighth sternite, neither of which characters are present in the new species. Moreover, in both sexes of the new species the pelta occupies at least $80 \%$ of the anterior margin of tergite II instead of scarcely $60 \%$, the meso-metanotal and the prothoracic notopleural sutures appear to be fused, the prosternal ferna are large, the mesopraesternum eroded medially and forming two transverse sclerites, the metathoracic sternopleural sutures not developed, and the tergites have only one pair of very small marginal setae. Thus Hexadikothrips and this new genus are considered not closely related, and their general similarities are probably due to the small body size and consequent reduction of many structural features. A further species that is similar in appearance is Adurothrips atopus Mound (1995a). This species is also minute and wingless with the terminal three segments of the antennae fused, but the hind coxae are wider apart than the mid coxae as in Urothrips Bagnall and related genera (Mound, 1972), the pelta is trilobed, the maxillary stylets wide apart in the head, and the second antennal segment bears an apical flange surrounding the base of the third segment.

\section{Senithrips psomus sp.n.}

(Figs 12 - 14)

Female aptera. Body colour light brown, head mainly golden with anterior margin darker, metanotal posterior and lateral margins pale; legs yellowish brown, tarsi yellow; antennal segments I-IV mainly yellow, terminal segment brown. With the structural details given above in the generic description.

Measurements. Holotype female in microns. Body length 1200. Head, length 200; maximum width 150. Pronotum, median length 110; width 200. Tergite IX setae S1 25; S2 
30; S3 40. Tube length 100; longest anal setae 45. Antennal segments I-VI length 25, 45, $30,37,35,80$.

Male aptera. Similar to female but smaller and paler.

\section{Material studied}

Holotype female aptera. Western Australia, Barrow Island, taken amongst Triodia angusta grassland with vaccum sampler, April/May, 2005, Jonathan Majer.

Paratypes: 9 우 $10^{x}$ taken at same or nearby site as holotype.

\section{Jacotia Faure}

This genus was based originally on a single species from South Africa, Jacotia elegiae Faure. Subsequently, three species were described from southern and eastern Australia, and an illustrated key to the four species was provided together with a redefinition of the genus (Mound, 1995b). Since then a further four species have been collected in various parts of Australia, and these are available in the Australian National Insect Collection, Canberra. One of these species is particularly distinctive and, as it is known from a good series, it is described here. All members of this genus are small and slender, with large eyes and short legs, and the dorsal surface is finely sculptured into complex patterns.

\section{Jacotia rhodorcha sp.n}

(Figs 15-17)

Female aptera. Body colour yellowish white with three longitudinal red stripes of internal pigment; tergite IX, posterior half of VIII and basal half of tube sharply dark brown (Fig. 17), head with frontal carina brown; antennal segments I, II and IV light brown, III mainly yellow but with brown mark at base, VI often yellow in basal half, VII and VIII brown. Head longer than wide, eyes longer dorsally than ventrally (Fig. 15); vertex with reticulate sculpture and markings within each reticle; postocular setae not developed; mouth cone rounded. Antennae 8-segmented (Fig. 16), VI-VIII broadly joined, III with basal stem slender but no sense cones, IV with 2 sense cones. Pronotum weakly reticulate, notopleural sutures weak, notopleural setae scarcely 10 microns long. Prosternal basantra absent; ferna transversely pointed; mesopraesternum (?spinasternum) transverse, separated from mesoeusternum with one pair of setae medially and another pair laterally; metathoracic sternopleural sutures absent. Meso and metanota with complex but weak sculpture. Pelta rectangular with margins rounded (Fig. 15); tergites with complex but weak sculpture, all setae minute on tergites II-VII; posteroangular setae on tergite VIII about 10 microns long; IX with marginal setae blunt. Sternites with transverse row of small discal setae, median marginal setae long. 

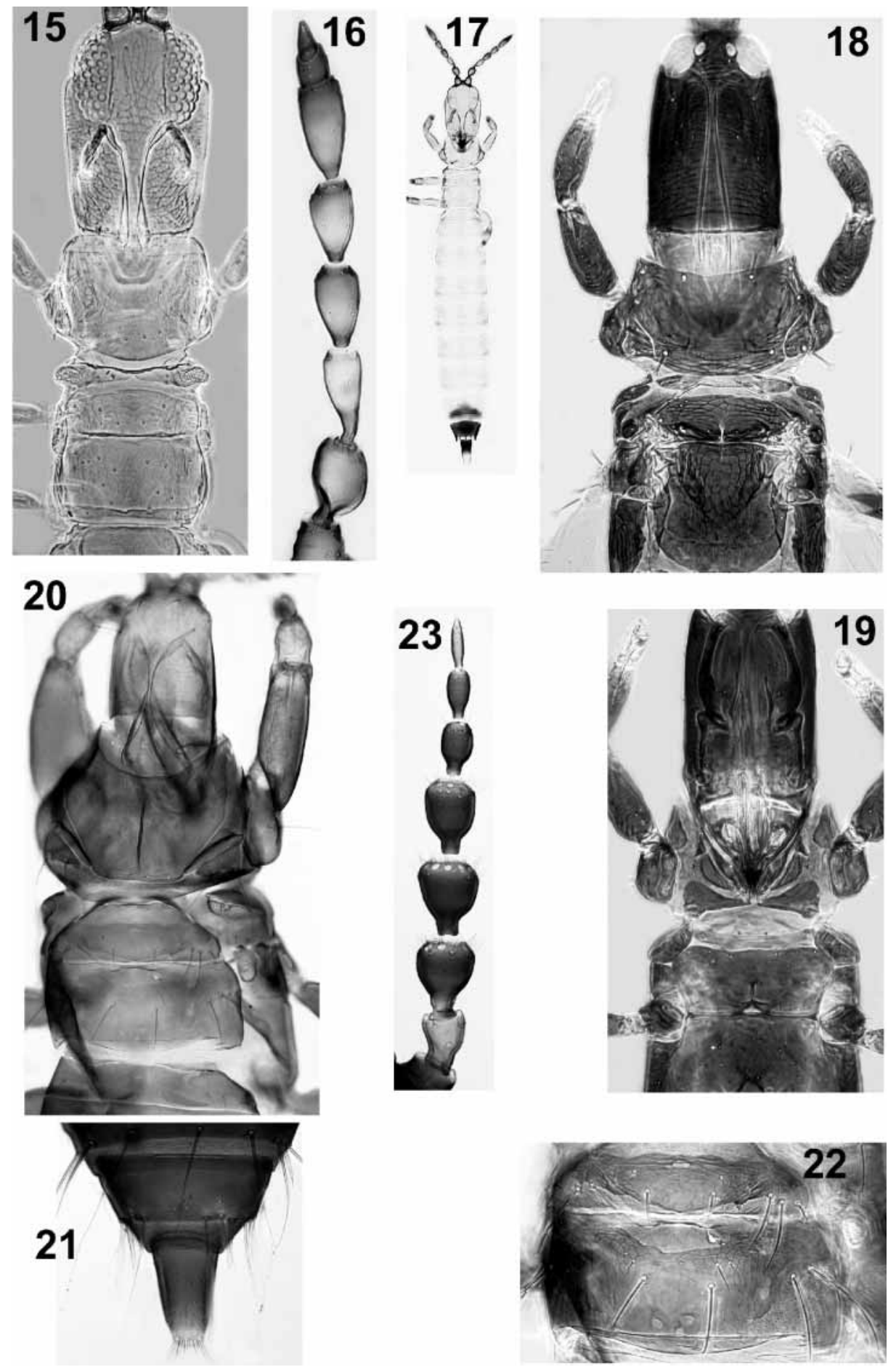

FIGURES 15-23. Jacotia, Stomothrips and Streptothrips species. (15) J. rhodorcha head and thorax; (16) J. rhodorcha antenna; (17) J. rhodorcha female; (18) Sto. mouldeni, dorsal; (19) Sto. mouldeni, ventral; (20) Str. tribulatius female aptera; (21) Str. tribulatius tergites VIII-X; (22) Str. tribulatius female aptera mesonotum and metanotum; (23) Str. tribulatius female macroptera antenna. 
Measurements. Holotype female in microns. Body length 1750. Head, length 250;

maximum width 165. Pronotum, length 120; median width 170; notopleural setae 10.

Tergite IX setae S1 15; S2 25; S3 10. Tube length 110. Antennal segments III-VIII length 50, 40, 40, 50, 20, 25.

Male aptera. Very similar to female in colour and structure, but smaller. Body length 1300 microns.

\section{Material studied}

Holotype female. Western Australia, Barrow Island, taken amongst Triodia angusta grassland with vaccum sampler, April/May, 2005, Jonathan Majer.

Paratypes: 21 우 $80^{\star}$ taken by vacuum sampler at same or nearby site as holotype.

\section{Comments}

According to the key to the four previously described species (Mound, 1995b), this new species shares the following two character states with $J$. elegiae Faure, the South African type-species of the genus: major setae on head, thorax and abdomen exceptionally short; body sculpture weakly defined but complex. The following characters states distinguish this species from J. elegiae: tube sharply bicoloured not brown (Fig. 17); base of the third antennal segment slender not expanded (Fig. 16). The most striking feature of this new species is the three longitudinal red stripes running the full length of the white body in adults and larvae.

\section{Stomothrips Okajima}

This genus was erected for a single Australian species, S. cycasi Okajima, taken on the leaves of Cycas calcicola in the Northern Territories, apparently feeding on fungal conidia (Okajima, 2000). The most characteristic feature of that species is the unusually elongate mouth cone that projects posteriorly to the metasternum. In contrast, in the new species described here from Cycas pruinosa, the mouth cone although long is directed ventrally and thus in slide-mounted specimens appears apically rounded. Despite this difference in orientation and appearance of the mouth cone, also an obvious difference in body colour, these two species are very similar in details of their structure. Their maxillary stylets are broader than in typical Phlaeothripinae, suggesting a possible relationship to the Docessissophothripini, although the males have no iridescent sculptured areas on the sternites. 
Female macroptera. Body colour light brown, tarsi paler; all major setae capitate and pale; antennal segments III-VI yellow; forewings pale. Head (Fig. 18) longer than wide, elevated in midline, with transversely reticulate weak sculpture laterally and posteriorly; maxillary stylets retracted to compound eyes, close together at anterior but diverging near posterior; mouth cone appearing rounded, apex directed ventrally, not extending beyond fore coxae. Antenae 8-segmented, III with 1 sense cone, IV with 2 sense cones. Pronotum with five pairs of major setae, notopleural sutures complete. Mesonotal lateral setae capitate; metanotum weakly reticulate, median setae acute. Prosternal basantra present, ferna transversely pointed medially, probasisternum eroded medially (Fig. 19); metathoracic sternopleural sutures absent. Fore tarsi unarmed. Forewings very weakly constricted, without duplicated cilia, sub-basal setae capitate. Pelta bell-shaped; tergites with 2 pairs of sigmoid wing-retaining setae of which each anterior pair is weaker than each marginal pair; tergites III - VI and VIII with two pairs of capitate setae laterally, VII and IX with setal pair S2 acute.

Measurements. Holotype female in microns. Body length 1840. Head, length 235; maximum width 145; postocular setae 30 . Pronotum, length 105; median width 200; major setae am 35, aa ?, ml 25, epim 50, pa 40. Forewing length 640; sub-basal setae 30, 25, 45. Tergite IX setae S1 75; S2 100. Tube length 130. Antennal segments III-VIII length 43, 45, 47, 43, 35, 25.

Male macroptera. Very similar to female in colour and structure, but smaller; sternites with no glandular areas; tergite IX setae S2 short and bluntly pointed.

\section{Material studied}

Holotype female. Western Australia, Kununurra Gorge, from Cycas pruinosa leaves, 23.ii.2005 (LAM 4575/76).

Paratypes: 12 females, 10 males taken with holotype.

\section{Comments}

In this new species the form, sculpture and chaetotaxy of the head, thorax and abdomen is closely similar to that of $S$. cycasi. In contrast to that species the body is considerably smaller, the body colour is brown not yellow, and the mouth cone projects ventrally not posteriorly. Other differences are: setal pair S2 on abdominal tergites VII and IX with apices acute not capitate; pronotal posteroangular setae scarcely 0.3 times as long as median length of pronotum instead of at least 0.5 ; sternal marginal setae scarcely twice as long as discal setae instead of about five times as long; mesopraesternum eroded medially instead of complete. This species is named in recognition of the many contributions of John Moulden to entomology in the north of Western Australia. 
This genus is one of ten genera placed in the Phlaeothripinae Tribe Plectrothripini (Okajima, 1981). Streptothrips includes two species that were described from southern Africa in Schizaea Faure, a genus synonymised by Priesner (1949), and the resultant eight species have been taken widely around the tropics; four from southern Africa, two from the Caribbean, and two from Sumatra. All of these species have several large stout sense cones on unusually stout median antennal segments, the eighth antennal segment is long and slender, and the eighth abdominal sternite bears a series of long and stout posteromarginal setae. A key to five species was provided by Okajima (1981), of which one was known only from apterae, and four only from macropterae. Two character states used in that key were subsequently recognised as being related to wing development, because Bournier (1992) described a species from Guadeloupe in which the third antennal segment of the aptera has no sense cones dorsally whereas that of the macroptera has two dorsal sense cones, and the paired ocellar setae are much longer in the aptera than the macroptera. The new species described here from Australia shows similar variation between morphs.

\section{Streptothrips tribulatius sp.n.}

(Figs 20-23)

Female macroptera. Body and antennae uniformly light brown, except antennal segment II, all tarsi and apex of tube paler; major setae light brown; forewing pale at base but darker at least medially (distal half of wings missing).

Head longer than wide, eyes well developed, postocular setae long and blunt, postocellar setae about as long as distance between ocelli; maxillary stylets retracted nearly to eyes, close together medially, maxillary guides stout. Antennal sense cones numerous (Fig. 23), 10 on III of which one or two are on the dorsal surface, 13 on IV, 9 on V; segment II with sensorium present on basal half of segment, VIII slender and about as long as VII. Pronotum with anteromarginal, anteroangular, midlateral and posteroangular pairs of setae scarcely longer than discal setae; notopleura with 2 pairs of long setae (Fig. 20). Prosternal basantra not present but with at least 6 pairs of setae; ferna irregularly circular; spinasternum eroded, mesopraesternum absent, anterior border of mesoeusternum with 5 pairs of long setae; metathoracic sternopleural suture short but broadly eroded. Fore tarsus with stout tooth and stout ventral hamus, fore femora without tubercle; mid and hind tibial apex each with two stout conical setae ventrally. Forewing with 2 sub-basal setae. Mesonotal lateral setae short. Metanotum reticulate with 2 pairs of long setae medially. Pelta broadly triangular with posterior margin eroded (as in femoralis). Abdominal tergite II eroded laterally, median tergites with no wing retaining setae but with 2 pairs of long marginal setae laterally and one pair of shorter median discal 
setae; tergite IX (Fig. 21) with 2 pairs of setae between S1 and S2, and another two pairs between S2 and S3, each of these pairs comprise one slender seta and one stout seta. Tube short, slightly constricted at apex, terminal setae short. Sternite VIII with transverse row of about 10 long setae, preceding sternites with long marginal setae, median pair longer than sternite length.

Measurements. Holotype female macroptera in microns. Body length 3000. Head, length 320; maximum width 250; postocular setae 75; postocellar setae 35 . Pronotum, length 225; median width 380; major setae am 40, aa 30, ml 25, epim 180 and 90, pa 30, pm 25. Forewing basal setae 50, 75. Tergite IX setae S1 175; stout supernumerary seta 75. Tube length 125; longest anal setae 75. Antennal segments III-VIII length 90, 85, 85, 60, 55,55 .

Female aptera. Colour similar to macroptera. Head with no ocelli (Fig. 20), compound eyes reduced to 3 ommatidia; postocular setae length 90, postocellar setae length 65 . Antennal sense cones less numerous, III with 3, IV with 5, V with 4 . Pronotum and prosternal sclerites similar to macroptera. Mesonotum and metanotum each with 3 pairs of long setae laterally (Fig. 22), metanotum without reticulation. Pelta strongly eroded; tergites, tube and sternites similar to macroptera.

Male aptera. Paler than female and slightly smaller, but similar in general appearance. Antennal segments III-V each with 3 to 5 sense cones. Pronotum with posteroangular and posteromarginal setae longer $(85,80)$. Meso and metanota each with about 5 setae laterally. Pelta scarcely developed; abdominal chaetotaxy similar to female, tergite IX with setae S2 stout; sternites without glandular areas, VIII with fewer marginal setae than female.

\section{Material studied}

Holotype macropterous female. Queensland, Cape Tribulation, from dead branch, 7.vii.1995 (LAM 2726).

Paratypes: 2 female apterae, 1 male aptera, collected with holotype.

\section{Comments}

The macropterous form of this new species is readily distinguished from the seven previously described species in which macropterae are known by the larger number of sense cones, 10 or more, on the third and fourth antennal segments. The apterous form is distinguished from the two species in which apterae are known by the much shorter setae on the anterior and lateral margins of the pronotum, all three pairs being less than 0.3 as long as the longest notopleural setae instead of more than 0.5 times as long. 
Bournier, A. (1992) Trois espèces nouvelles de la Guadeloupe. Bulletin de la Société entomologique de France, 96, 365-374.

Crespi, B.J., Morris, D.C. \& Mound, L.A. (2004) Evolution of ecological and behavioural diversity: Australian Acacia thrips as model organisms. Australian Biological Resources Study \& Australian National Insect Collection, CSIRO, Canberra, Australia, 328 pp.

CSIRO (ed.). (1970) The Insects of Australia. A Textbook for Students and Research Workers. Melbourne University Press, Carlton, 1029 pp.

Mound, L.A. (1972) Species complexes and the generic classification of leaf-litter thrips of the Tribe Urothripini (Phlaeothripidae). Australian Journal of Zoology, 20, 83-103.

Mound, L.A. (1976) American leaf-litter Thysanoptera of the genera Erkosothrips, Eurythrips and Terthrothrips (Phlaeothripidae: Phlaeothripinae). Bulletin of the British Museum (Natural History). Entomology, 35, 27-64.

Mound, L.A. (1977) Species diversity and the systematics of some New World leaf-litter Thysanoptera (Phlaeothripinae; Glyptothripini). Systematic Entomology, 2, 225-244.

Mound, L.A. (1995a) Homoplasy and the systematics of phlaeothripine Thysanoptera, with a new short-tubed Australian Urothripine. Courier Forschunginstitut Senckenberg, 178, 21-25.

Mound, L.A. (1995b) Jacotia (Phlaeothripidae), a second genus of Thysanoptera with disjunct distribution between Australia and South Africa. Journal of the Australian Entomological Society, $34,90-94$.

Mound, L.A. (1996) Thysanoptera. In: Wells, A., Zoological Catalogue of Australia. Volume 26. Psocoptera, Phthiraptera, Thysanoptera. Melbourne. CSIRO Australia, pp. 249-336, 397-414 (Index).

Mound, L.A. (2002) Zemiathrips; a new genus of fungus-feeding phlaeothripine Thysanoptera in Australian leaf-litter. Australian Journal of Entomology, 41, 209-215.

Mound, L.A. \& Palmer, J.M. (1983) The generic and tribal classification of spore-feeding Thysanoptera (Phlaeothripidae: Idolothripinae). Bulletin of the British Museum (Natural History). Entomology, 46, 1-174.

Okajima, S. (1981) A revision of the tribe Plectrothripini of fungus-feeding Thysanoptera (Phlaeothripidae: Phlaeothripinae). Systematic Entomology, 6, 291-336.

Okajima, S. (2000) The first cycad-associated thrips in the family Phlaeothripidae, Stomothrips cycasi, gen. et sp. nov. (Thysanoptera). Invertebrate Taxonomy, 14, 705-708.

Priesner, H. (1949) Genera Thysanopterorum. Keys for the identification of the genera of the order Thysanoptera. Bulletin de la Société Royal Entomologique d'Egypte, 33, 31-157. 